\title{
ANALOGUES OF RELATIVISTIC INTEGRALS: THEIR APPLICATION IN R-MATRIX METHOD FOR HIGHLY CHARGED TUNGSTEN IONS
}

\author{
V. Jonauskas, R. Kisielius, Š. Masys, and A. Kynienė \\ Institute of Theoretical Physics and Astronomy, Vilnius University, A. Goštauto 12, LT-01108 Vilnius, Lithuania \\ E-mail: valdas.jonauskas@tfai.vu.lt
}

Received 26 January 2013; revised 30 May 2013; accepted 20 June 2013

\begin{abstract}
The electron-impact collision strength calculations using different $\mathrm{R}$-matrix code versions are performed for the $1 s^{2} 2 s^{2} 2 p^{6} 3 s^{2} 3 p^{6} 3 d^{10} 4 l(l=0,1,2,3)$ configuration levels of the $\mathrm{W}^{45+}$ ion. The influence of relativistic effects on the bound-bound, bound-continuum, and continuum-continuum integrals of the collision strength is studied in quasirelativistic and relativistic approximations. A suitability of our introduced relativistic integrals method for highly charged ions is cross-checked by comparing results of different relativistic calculation methods.
\end{abstract}

Keywords: excitation, relativistic, tungsten

PACS: $31.30 . j c, 34.80 . D p$

\section{Introduction}

In order to obtain emission-line spectra or energy losses from plasma impurities, one needs to solve the balance equation which determines level populations for the ions of different ionization stages. In its turn, the balance equation requires a detailed knowledge of accurate atomic data describing atomic structure (energy levels, radiative transition probabilities, Auger transition rates) and photon or charged particle scattering from the ionized atoms.

The scattering problem has to do with all different processes that can occur after collision of a photon or charged particle with an ion. Both theoretical and experimental methods of obtaining scattering parameters are very complicated, especially when dealing with heavy and/or highly charged ions. Consequently, there is a real need for the sophisticated theoretical methods allowing to simplify or to reduce calculations required for a large scale scattering data generation unavoidable in plasma modelling databasis realization.
There exist several theoretical methods to calculate the cross sections necessary for practical applications. One of the most accurate and suitable techniques to solve the scattering problem is the Rmatrix method [1]. This method includes nearly all of the physical effects that contribute to cross sections and is applicable to all kinds of atoms, from neutral ones to highly ionized stages.

These calculations are prohibitively large and extremely time-consuming if performed in the relativistic coupling using, for example, the DiracFock R-matrix method [2] because the accuracy of results depends on the number of target levels included (which is significantly larger compared to a non-relativistic $L S$-term case). On the other hand, the methods based on transformation of $S$ - and $K$ matrices [3-5], calculated in the pure LS-coupling, to intermediate coupling can help to overcome the problem because the number of terms is significantly smaller than the number of corresponding finestructure levels making these terms. On the negative side, only the non-relativistic wave functions 
(and, consequently, non-relativistic interaction integrals) are used in the LS-coupling. This kind of approximation becomes unsuitable and unsustainable when one has to deal with the highly charged heavy ions where it is extremely important to use the relativistic wave functions and the suitable relativistic approximations.

We have developed an approach based on the analogues of the relativistic integrals (ARI) [6] which enables one to utilize relativistic wave functions obtained in the Dirac-Fock approximation. By this both the direct and indirect relativistic effects are included in the final result. The direct effects arrise when the masses of electrons increase due to the speed of electrons, and the electrons are pushed closer to the nucleus. Since the inner electrons move with larger speeds than outer ones, their mean distance from the nucleus changes more notably when compared with the mean distances obtained in non-relativistic calculations. Therefore, the inner electrons screen the charge of the centrally placed nucleus more effectively. Due to this screening, the outer electrons are pushed away from the nucleus inducing the indirect relativistic effects.

The goal of the present research is an assessment of different R-matrix methods used in the calculations of atomic data for electron scattering from the highly charged tungsten ions and estimation of the importance of relativistic effects in the case of the electron-impact excitation from the outer shells of heavy ions. The collision strengths for the electronimpact excitation among the levels of the configurations with one electron in the outer $4 \mathrm{~s}, 4 \mathrm{p}, 4 \mathrm{~d}, 4 \mathrm{f}$ shells of $\mathrm{W}^{45+}$ are being determined when the different approaches to include the relativistic effects are adopted.

\section{Expressions for analogues of relativistic integrals}

The main relations for analogues of relativistic integrals and methods used to find their expressions have been presented earlier [6-8]. In the current work we will present only the relations employed in our calculations with the R-matrix code which implements the intermediate coupling frame transformation (ICFT) [5]. The code includes one- electron integrals of operators for kinetic and potential energies in the field of the nucleus. The one-elec- tron part of operators is extended by adding massvelocity corrections and Darwin terms. All these relativistic corrections are replaced by general expressions for one-electron integrals:

$$
I\left(n l, n^{\prime} l\right)=\frac{1}{4 l+2} \sum_{j}[j] I\left(n l j, n^{\prime} l j\right),
$$

where

$$
\begin{aligned}
& I\left(n l j, n^{\prime} l j\right)=\int_{0}^{\infty}\left\{-2 c^{2} Q_{n \bar{l} j}(r) Q_{n^{\prime} j j}(r)+c Q_{n \bar{l} j}(r)\left[\frac{\mathrm{d} P_{n^{\prime} j}(r)}{\mathrm{d} r}+\frac{\kappa}{r} P_{n^{\prime} j}(r)\right]\right. \\
& -c P_{n l j}(r)\left[\frac{\mathrm{d} Q_{n \bar{l} j}(r)}{\mathrm{d} r}-\frac{\kappa}{r} Q_{n^{\prime} j}(r)\right] \\
& \left.-\frac{Z}{r}\left(P_{n l j}(r) P_{n^{\prime} j j}(r)+Q_{n i j}(r) Q_{n^{\prime} j}(r)\right)\right\} \mathrm{d} r .
\end{aligned}
$$

The functions $P_{n l j}(r)$ and $Q_{n \bar{j}}(r)$ are, correspondingly, large and small components of the relativistic single-electron wave function.

The expression for a nonrelativistic integral of Coulomb interaction includes summation over relativistic integrals:

$$
\begin{aligned}
& R^{k}\left(n_{1} l_{1}, n_{2} l_{2}, n_{3} l_{3}, n_{4} l_{4}\right) \\
& =\frac{1}{4} \sum_{j_{1} j_{2} j_{3}}\left[j_{1}, j_{2}, j_{3}, j_{4}\right]\left\{\begin{array}{l}
j_{1} j_{3} k \\
l_{3} l_{1} 1 / 2
\end{array}\right\}^{2} \quad\left\{\begin{array}{l}
j_{2} j_{4} k \\
l_{4} l_{2} 1 / 2
\end{array}\right\}^{2} \\
& \times\left[R^{k}\left(n_{1} l_{1} j_{1}, n_{2} l_{2} j_{2}, n_{3} l_{3} j_{3}, n_{4} l_{4} j_{4}\right)+R^{k}\left(n_{1} l_{1} j_{1}, n_{2} \bar{l}_{2} j_{2}, n_{3} l_{3} j_{3}, n_{4} \bar{l}_{4} j_{4}\right)\right. \\
& \left.+R^{k}\left(n_{1} \bar{l}_{1} j_{1}, n_{2} l_{2} j_{2}, n_{3} \bar{l}_{3} j_{3}, n_{4} l_{4} j_{4}\right)+R^{k}\left(n_{1} \bar{l}_{1} j_{1}, n_{2} \bar{l}_{2} j_{2}, n_{3} \bar{l}_{3} j_{3}, n_{4} \bar{l}_{4} j_{4}\right)\right],
\end{aligned}
$$

where $n l j$ corresponds to a large component and $n \bar{l} j$ to a small component of the wave function in the $R^{k}$ integrals. The first integral in the brackets of (3) represents the relativistic analogue of the Coulomb interaction integral, the next two integrals take into account the two-electron Darwin correction.

In the nonrelativistic approximation, the oneelectron spin-orbit and the main part of spin-other-orbit interactions are taken into account using a spin-orbit constant:

$$
\begin{aligned}
& \zeta_{n l, n^{\prime} l}^{Z}=-Z \alpha^{2}[l(l+1)(2 l+1)]^{-1} \\
& \times \sum_{j}(2 j+1)[j(j+1)-l(l+1)-3 / 4] I\left(n l j, n^{\prime} l j\right) .
\end{aligned}
$$

A different formula for the spin-orbit constant was presented in the work [8].

\section{Results and discussion}

As an initial step for the electron-ion scattering calculations, the basis of relativistic wave 
functions based on the Dirac-Fock type radial orbitals was determined. Relativistic wave functions were determined for the ground and the excited states with an outer electron in $4 l$ shells of the $\mathrm{W}^{45+}$ ions, when $l=0,1,2,3$. In the case of quasirelativistic calculations, the target orbitals were generated with the AUTOSTRUCTURE code [ 9 , 10] (http://amdpp.phys.strath.ac.uk/autos/). Alternatively, the GRASP0 code [11] (http://www. am.qub.ac.uk/DARC) was adopted for the completely relativistic wave function calculation.

Using the obtained wave functions, we have calculated energy level spectra in a completely relativistic Dirac-Fock approach applying the configuration interaction (CI) method. This calculation includes all seven energy levels from the $n=4$ complex. The relativistic R-matrix calculation employing the regular scattering codes from the DARC program [2] have been performed and electron-impact collision strength values were obtained. These data serve as a benchmark point for the comparison with the data obtained from the quasirelativistic R-matrix method based on the multichannel quantum defect theory and the intermediate coupling frame transformation with and without non-relativistic interaction integrals replaced by their relativistic versions.

The calculation results obtained for the energy levels in the $\mathrm{W}^{45+}$ ion using three different approaches are presented in Table 1. One can say with certainty that results which include relativistic Dirac-Fock functions agree very well. The difference between their energies does not exceed $0.8 \mathrm{Ry}$ for absolute energy values. If compared with respect to the ground $4 \mathrm{~s}_{1 / 2}$ level, the energies agree within $0.02 \mathrm{Ry}$, except for the largest discrepancy of 0.1 Ry determined for the $4 \mathrm{p}_{1 / 2}$ level.
The fine-structure splitting for the considered configurations agree even better. It is worth to notice that spin-orbit splitting between levels of $4 l_{l-1 / 2}$ and $4 l_{l+1 / 2}$ configurations is smaller in calculations which employ analogues of relativistic integrals than the splitting values obtained from the fully relativistic approach. It means that our spin-orbit constant obtained from Eq. (4) provides underestimated values. The largest disagreement of $0.11 \mathrm{Ry}$ is obtained for the $4 \mathrm{p}$ configuration levels while discrepancy for the $4 \mathrm{f}$ configuration levels does not exceed 0.02 Ry. On the other hand, the quasirelativistic approach gives deviation from relativistic calculations for spin-orbit splitting of $1.5 \mathrm{Ry}$ for the $4 \mathrm{p}$ configuration, while for the $4 \mathrm{f}$ configuration, the splitting is larger by approximately $0.1 \mathrm{Ry}$. This confirms the fact that indirect relativistic effects are taken into account when relativistic wave functions are obtained by solving Dirac-Fock equations. Furthermore, all absolute values of the level energies are higher in quasirelativistic calculations than the calculated relativistic energies by approximately 257 Ry. Agreement for the energies relative to the ground level is much worse in this case too.

Our calculated energy levels are compared to the relativistic calculation data taken from [12]. In the latter study, 25 levels of $\mathrm{W}^{45+}$ were included in the target wave function CI expansion in order to perform relativistic R-matrix calculation. It is evident from Table 1 that the data from our completely relativisitic calculation (DARC) are of the same quality as those from [12].

The data for collision strengths obtained using different approaches for three transitions in $\mathrm{W}^{45+}$ ions are presented in Figs. 1-2. We have adopted 1.6 a.u. R-matrix radius in all three calculations which included 25 continuum orbitals for each

Table 1. Energy levels (in Ry) for the $1 \mathrm{~s}^{2} 2 \mathrm{~s}^{2} 2 \mathrm{p}^{6} 3 \mathrm{~s}^{2} 3 \mathrm{p}^{6} 3 \mathrm{~d}^{10} 4 l(l=0,1,2,3)$ configurations of $\mathrm{W}^{45+}$ obtained with the relativistic R-matrix code (DARC), quasirelativistic R-matrix code (ICFT), and quasirelativistic R-matrix code that uses the relativistic analogues of integrals (ARI). Results of 25-level calculation from [12] are noted as GRASP25.

\begin{tabular}{ccccccc}
\hline Index & Level & DARC & ICFT & ARI & GRASP25 \\
\hline 1 & $4 \mathrm{~s}_{1 / 2}$ & -29529.183 & -29271.875 & -29528.497 & - \\
\hline 2 & $4 \mathrm{p}_{1 / 2}$ & 7.217 & 6.796 & 7.309 & 7.220 \\
\hline 3 & $4 \mathrm{p}_{3 / 2}$ & 14.729 & 12.810 & 14.715 & 14.733 \\
\hline 4 & $4 \mathrm{~d}_{3 / 2}$ & 25.856 & 23.911 & 25.874 & 25.859 \\
\hline 5 & $4 \mathrm{~d}_{5 / 2}$ & 27.470 & 25.468 & 27.458 & 27.474 \\
\hline 6 & $4 \mathrm{f}_{5 / 2}$ & 39.328 & 37.762 & 39.332 & 39.331 \\
\hline 7 & $4 \mathrm{f}_{7 / 2}$ & 39.747 & 38.283 & 39.738 & 39.751 \\
\hline
\end{tabular}




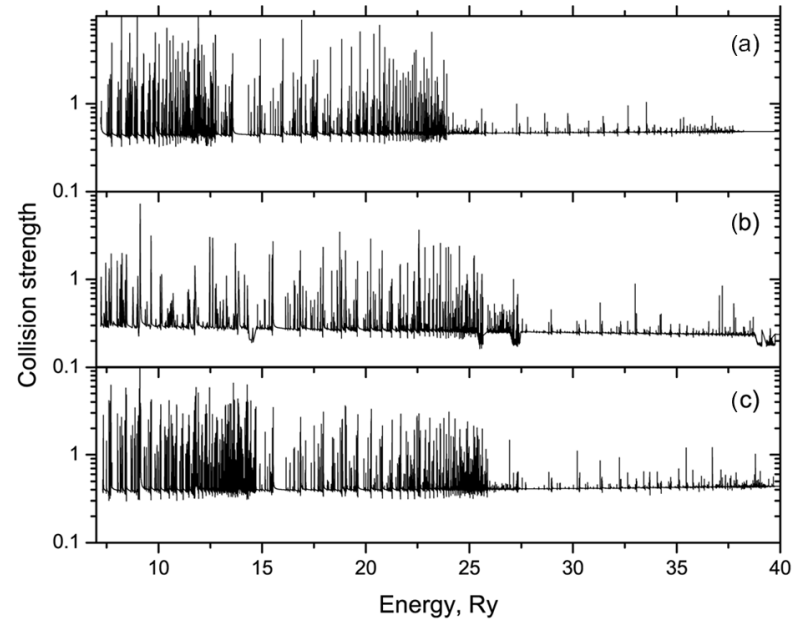

Fig. 1. Electron-impact excitation collision strengths for the $4 \mathrm{~s}_{1 / 2}-4 \mathrm{p}_{1 / 2}$ transition in $\mathrm{W}^{45+}$. Data have been obtained with (a) the quasirelativistic R-matrix code (ICFT), (b) the relativistic R-matrix code (DARC), and (c) the same quasirelativistic R-matrix code with the relativistic analogues of integrals adopted.

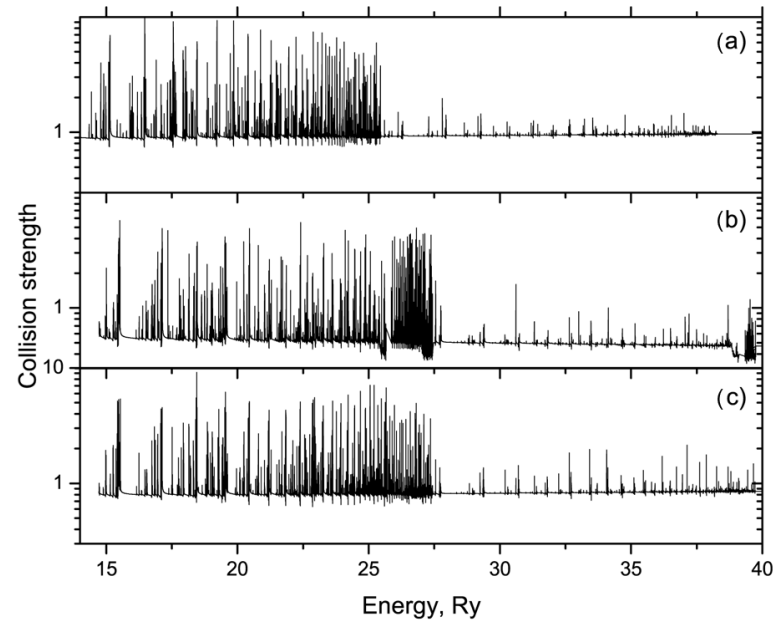

Fig. 2. Electron-impact excitation collision strengths for the $4 \mathrm{~s}_{1 / 2}-4 \mathrm{p}_{3 / 2}$ transition in $\mathrm{W}^{45+}$. Data have been obtained with (a) the quasirelativistic R-matrix code (ICFT), (b) the relativistic R-matrix code (DARC), and (c) the same quasirelativistic R-matrix code with the relativistic analogues of integrals adopted.

channel angular momentum in the expansion of the wave function. In the DARC calculations, the target consist of 7 levels, the maximum number of channels for a partial wave is 32 , and the size of the corresponding Hamiltonian matrix is 808. In the non-relativistic scattering calculations without and with analogues of relativistic integrals, the target has 4 terms, the maximum number of channels is

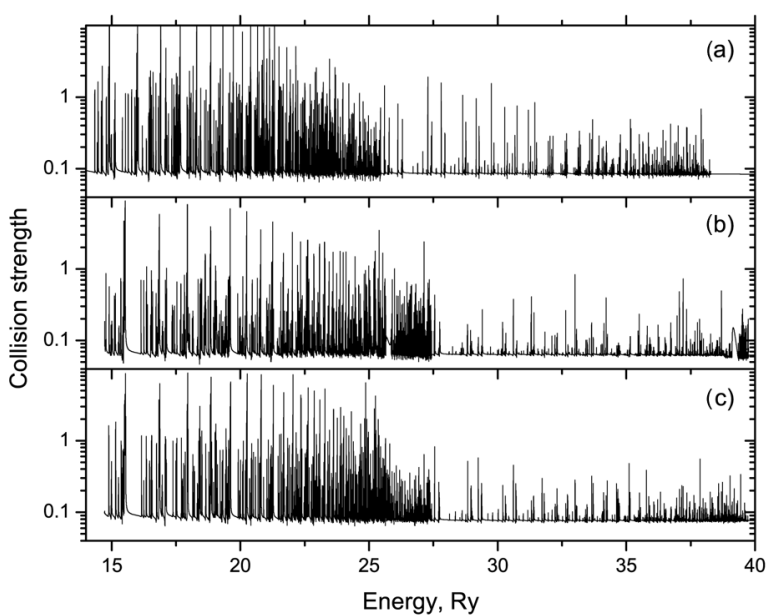

Fig. 3. Electron-impact excitation collision strengths for the $4 p_{1 / 2}-4 p_{3 / 2}$ transition in $W^{45+}$. Data have been obtained with (a) the quasirelativistic R-matrix code (ICFT), (b) the relativistic R-matrix code (DARC), and (c) the same quasirelativistic R-matrix code with the relativistic analogues of integrals adopted.

10, and the size of the corresponding Hamiltonian matrix is 250 . We have included all partial waves with angular momentum $J \leq 29$ in all three cases. No top-up procedures are taken into account. It can be seen that the resonance structure in DARC and ARI cases are very similar. Some differences can be explained by the different energy mesh employed in the codes. Although agreement between various relativistic data is good, the collision strengths obtained with the ARI approach are slightly higher than those calculated in the completely relativistic (DARC) approximation. The reason of the differences is not clear so far.

One can notice some prominent 'dips' in collision strength values calculated using the DARC code for the excitation to $4 \mathrm{p}_{1 / 2}$ and $4 \mathrm{p}_{3 / 2}$ levels at incident electron energies close to $25 \mathrm{Ry}$. These irregularities can be attributed to the malfunctioning of this code for the outer region.

In Table 2, we present effective collision strengths for the 1-2,1-3, and 2-3 excitations in the $\mathrm{W}^{45+}$ ion. A good agreement between two relativistic approaches is evident at low tempretures, where the resonance contribution makes the most part of effective collision strengths. For all three excitations, effective collision strengths increase with the tempreture increasing in ARI case, while their values from ICFT calculations have a decreasing character. On the other hand, DARC values show 
Table 2. Comparison of effective collision strengths for the $4 \mathrm{~s}_{1 / 2}-4 \mathrm{p}_{1 / 2}, 4 \mathrm{~s}_{1 / 2}-4 \mathrm{p}_{3 / 2}$, and $4 \mathrm{p}_{1 / 2}-4 \mathrm{p}_{3 / 2}$ excitations in the $\mathrm{W}^{45+}$ ion determined using the quasirelativistic R-matrix code (ICFT), fully relativistic R-matrix code (DARC), and analogues of relativistic integrals (ARI) method.

\begin{tabular}{ccccccccccc}
\hline & \multicolumn{3}{c}{$4 \mathrm{~s}_{1 / 2}-4 \mathrm{p}_{1 / 2}$} & \multicolumn{3}{c}{$4 \mathrm{~s}_{1 / 2}-4 \mathrm{p}_{3 / 2}$} & \multicolumn{3}{c}{$4 \mathrm{p}_{1 / 2}-4 \mathrm{p}_{3 / 2}$} \\
\hline $\mathrm{T}(\mathrm{K})$ & ICFT & DARC & ARI & ICFT & DARC & ARI & ICFT & DARC & ARI \\
\hline 500 & 0.68 & 0.45 & 0.48 & 1.15 & 0.51 & 0.87 & 0.24 & 0.11 & 0.11 \\
\hline 750 & 0.69 & 0.51 & 0.54 & 1.14 & 0.55 & 0.95 & 0.23 & 0.11 & 0.12 \\
\hline 1000 & 0.69 & 0.56 & 0.57 & 1.12 & 0.56 & 0.99 & 0.21 & 0.11 & 0.12 \\
\hline 1500 & 0.69 & 0.59 & 0.61 & 1.09 & 0.58 & 1.04 & 0.19 & 0.11 & 0.12 \\
\hline 2000 & 0.70 & 0.61 & 0.63 & 1.06 & 0.59 & 1.06 & 0.18 & 0.11 & 0.13 \\
\hline 3000 & 0.70 & 0.59 & 0.65 & 1.02 & 0.60 & 1.08 & 0.16 & 0.12 & 0.13 \\
\hline 5000 & 0.70 & 0.54 & 0.65 & 0.98 & 0.60 & 1.10 & 0.14 & 0.12 & 0.13 \\
\hline 7500 & 0.70 & 0.49 & 0.64 & 0.96 & 0.59 & 1.11 & 0.13 & 0.12 & 0.15 \\
\hline 10000 & 0.70 & 0.46 & 0.64 & 0.95 & 0.59 & 1.13 & 0.13 & 0.12 & 0.15 \\
\hline
\end{tabular}

a slightly increasing tendency. The reason of these differences is still unclear.

\section{Conclusions}

For highly and heavy elements, the relativistic wave functions have to be employed in atomic calculations. The approach where non-relativistic integrals are substituted for their relativistic analogues extends possible application of available computer codes. A fairly good agreement with DiracFock values is obtained for the energy levels of $1 \mathrm{~s}^{2} 2 \mathrm{~s}^{2} 2 \mathrm{p}^{6} 3 \mathrm{~s}^{2} 3 \mathrm{p}^{6} 3 \mathrm{~d}^{10} 4 l(l=0,1,2,3)$ configurations of $\mathrm{W}^{45+}$ ion when calculations are performed with relativistic analogues of integrals. However, the data from quasirelativistic approximation employing corresponding wave functions exibit larger discrepancies. The difference from relativistic energies is approximately $257 \mathrm{Ry}$ for the absolute values of energies. Furthermore, the applied quasirelativistic approach overestimates the spin-orbit splitting for the considered configurations. This demonstrates the fact that the indirect relativistic effects are taken into account with relativistic two-component radial wave functions when valence electrons are more effectively screened from the nucleus. Consequently, they are pushed away from the nucleus, and their velocities decrease. This affects the value of the spin-orbit constant as well.

A comparison of electron-impact excitation collision strengths obtained with relativistic and quasirelativistic wave functions for the transitions in the $\mathrm{W}^{45+}$ ions is presented and discussed. The agreement of the calculated collision strengths with Dirac-Fock values is evident for the approach where analogues of relativistic integrals are utilized. The quasirelativistic calculations slightly overstimate collision strengths if compared with the approaches where relativistic wave functions are used.

\section{Acknowledgments}

This work was partly supported by the European Commission under the Contract of Association between EURATOM and Lithuanian Energy Institute and was carried out within the framework of the European Fusion Development Agreement.

\section{References}

[1] P.G. Burke, A. Hibbert, and W.D. Robb, Electron scattering by complex atoms, J. Phys. B 4, 153-161 (1971).

[2] S. Ait-Tahar, I.P. Grant, and P.H. Norrington, Electron scattering by Fe XXII within the Dirac R-matrix approach, Phys. Rev. A 54, 3984-3989 (1996).

[3] H.E. Saraph, Fine structure cross sections from reactance matrices - a more versatile development of the program jajom, Comput. Phys. Comm. 15, 247-258 (1978).

[4] M. Aymar, C.H. Greene, and E. Luc-Koenig, Multichannel spectroscopy of complex atoms, Rev. Mod. Phys. 68, 1015-1123 (1996).

[5] D.C. Griffin, N.R. Badnell, and M.S. Pindzola, R-matrix electron-impact excitation cross sections in intermediate coupling: an MQDT transformation approach, J. Phys. B: At. Mol. Opt. Phys. 31, 3713-3727 (1998).

[6] V. Jonauskas, F.P. Keenan, R. Kisielius, P.A.M. van Hoof, M.E. Foord, R.F. Heeter, S.J. Rose, 
G.J. Ferland, and P.H. Norrington, Relativistic analogues of nonrelativistic integrals in R-matrix calculations, J. Phys. B: At. Mol. Opt. Phys. 38, L79-L85 (2005).

[7] R. Karazija and V. Jonauskas, Investigation of the relativistic equivalent Hamiltonian in the LS coupling scheme. J. Mat. Phys. 42, 5642-5651 (2001).

[8] V. Jonauskas and R. Karazija, General relations between radial integrals in nonrelativistic and relativistic calculation schemes, J. Math. Phys. 44, 1660-1665 (2003).

[9] N.R. Badnell, Dielectronic recombination of $\mathrm{Fe}^{22+}$ and $\mathrm{Fe}^{21+}$, J. Phys. B: At. Mol. Phys. 19, 3827-3835 (1986).
[10]N.R. Badnell, On the effects of the two-body non-fine-structure operators of the Breit-Pauli Hamiltonian, J. Phys. B: At. Mol. Opt. Phys. 30, 1-11 (1997).

[11]I.P. Grant, B.J. McKenzie, P.H. Norrington, D.F. Mayers, and N.C. Pyper, An atomic multiconfigurational Dirac-Fock package, Comput. Phys. Comm. 21, 207-231 (1980).

[12]C.P. Ballance and D.C. Griffin, Electron-impact excitation of $\mathrm{W}^{44+}$ and $\mathrm{W}^{45+}$, J. Phys. B: At. Mol. Opt. Phys. 40, 247-258 (2007).

\title{
R-MATRICOS METODO SU RELIATYVISTINIU INTEGRALU ANALOGAIS TAIKYMAS STIPRIAI JONIZUOTIEMS VOLFRAMO JONAMS
}

\author{
V. Jonauskas, R. Kisielius, Š. Masys, A. Kynienè \\ Vilniaus universiteto Teorines fizikos ir astronomijos institutas, Vilnius, Lietuva
}

\begin{abstract}
Santrauka
Elektronų ir fotonų sklaidos uždaviniams spręsti naudojamas R-matricos metodas yra vienas tiksliausių, nes atsižvelgia ị visus pagrindinius fizikinius procesus, vykstančius sklaidos metu. Skaičiavimai R-matricos metodu yra labai sudetingi ir reikalauja daug laiko, ypač jei jie atliekami visiškai reliatyvistiniame artinyje. Kvazireliatyvistinis R-matricos metodas, kai iš pradžių nagrinejjami nereliatyvistiniai $L S$ termai, o vèliau transformaciju pagalba pereinama prie smulkiosios sandaros lygmenų, yra greitesnis, tačiau netinkamas sunkiesiems elementams, nes nevisiškai atsižvelgia $\mathfrak{i}$ reliatyvistinius efektus. Darbe palyginti energijos lyg-
\end{abstract}

menys ir sužadinimų elektronais stipriai, suskaičiuoti naudojant tris skirtingus reliatyvistinius R-matricos metodus: Dirako ir Foko, kvazireliatyvistini bei reliatyvistiniu integralu analogus kvazireliatyvistineje $\mathrm{R}$-matricos programoje. Skaičiavimai atlikti $\mathrm{W}^{45+}$ jono $n=4$ lygmenims. Dirako ir Foko R-matricos metodu gautos vertès buvo atskaitos taškas palyginimui su kitais nagrinètais metodais. Parodyta, kad naudojant reliatyvistinių integralų analogus kvazireliatyvistineje R-matricos programoje galima atsižvelgti i tiesioginius ir netiesioginius reliatyvistinius efektus, kurie automatiškai yra įtraukiami Dirako ir Foko artinio atveju. 